ASSESSMENT OF LIVELIHOOD VULNERABILITY DUE TO CLIMATE CHANGE OF THE LOCAL PEOPLE IN DINH HOA DISTRICT, THAI NGUYEN PROVINCE

Bui Thi Minh $\mathrm{Ha}^{1 *}$, Nguyen Huu Tho ${ }^{2}$, Le Thi Hong Phuong ${ }^{3}$, Tran Viet Dung ${ }^{1}$

${ }^{I} T N U$ - University of Agriculture and Forestry

${ }^{2}$ Thai Nguyen University

${ }^{3}$ Hue University of Agriculture and Forestry, Hue University

\begin{tabular}{|c|c|c|}
\hline \multicolumn{2}{|c|}{ ARTICLE INFO } & ABSTRACT \\
\hline Received: & $13 / 10 / 2021$ & The study used the Livelihood Vulnerability Index (LVI) as a method to \\
\hline Revised: & $08 / 11 / 2021$ & $\begin{array}{l}\text { assess the vulnerability of household livelihoods to the impacts of climate } \\
\text { change. Based on the average value of the main components in LVI to give }\end{array}$ \\
\hline Published: & 08/11/2021 & the LVI-IPPC index with the presence of 3 factors: exposure, sensitivity \\
\hline \multicolumn{2}{|l|}{ KEYWORDS } & pacts of climate change in the locality are relatively high, reaching \\
\hline \multicolumn{2}{|l|}{ Climate change } & adaptive capacity of 0.417 means that the current adaptive capacity of the \\
\hline \multicolumn{2}{|l|}{ Vulnerability } & community to the impacts of climate change is relatively good. The final \\
\hline \multicolumn{2}{|l|}{ Livelihood } & s results show that the LIV-IPCC index of Dinh Hoa district has a \\
\hline \multicolumn{2}{|l|}{ Dinh Hoa district } & $\begin{array}{l}\text { lue of }-0.020 \text {, in which upland communes are more vulnerable tha } \\
\text { wland communes with LIV-IPCC values of }-0.015 \text { and }-0.023 \text {. }\end{array}$ \\
\hline
\end{tabular}

Thai Nguyen province

\title{
ĐÁNH GIÁ TÍNH DẼ̃ BỊ TỔN THƯƠNG SINH KẾ DO BIẾN ĐỔI KHÍ HậU ĐỐI VỚI NGƯỜI DÂN HUYỆN ĐỊNH HÓA, TỈNH THÁI NGUYÊN
}

\author{
Bùi Thị Minh Hà ${ }^{*}$, Nguyễn Hữu Thọ ${ }^{2}$, Lê Thị Hồng Phương ${ }^{3}$, Trần Việt Dũng ${ }^{1}$ \\ ${ }^{1}$ Trưòng Đại học Nông lâm - ĐH Thái Nguyên \\ ${ }^{2}$ Đại học Thái Nguyên \\ ${ }^{3}$ Truò̀ng Đại học Nông lâm - Đại học Huế
}

\begin{tabular}{|c|c|}
\hline THÔNG TIN BÀI BÁO & TÓM TẮT \\
\hline Ngày nhân bài: $\quad 13 / 10 / 2021$ & \multirow{10}{*}{ 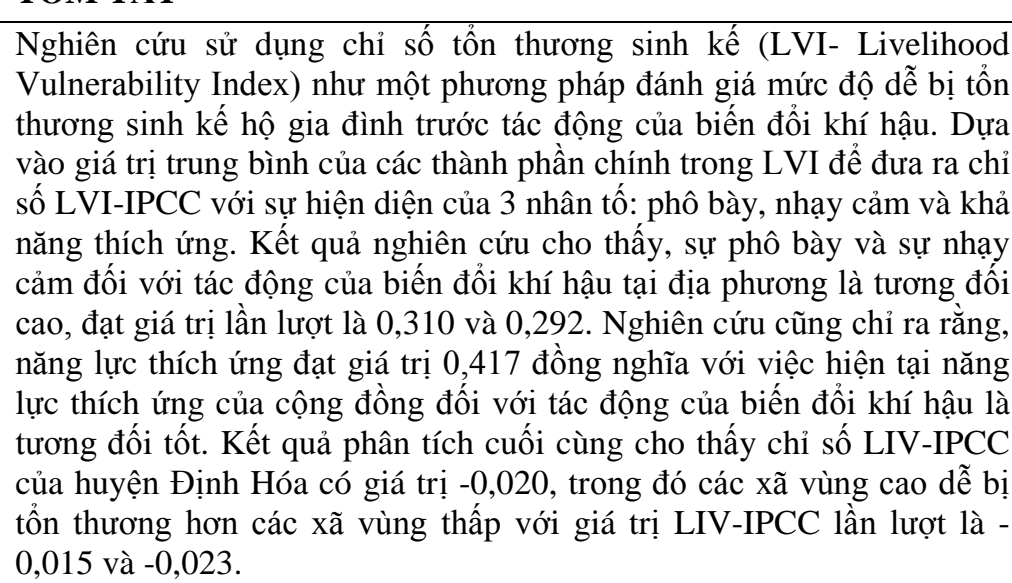 } \\
\hline Ngày hoàn thiên: & \\
\hline & \\
\hline & \\
\hline TÙ KHÓA & \\
\hline Biến đổi kl & \\
\hline Tổn thương & \\
\hline Sinh kế & \\
\hline Huyện Định Hóa & \\
\hline Tỉnh Thái Nguyên & \\
\hline
\end{tabular}

DOI: $\underline{\text { https://doi.org/10.34238/tnu-jst.5149 }}$

\footnotetext{
* Corresponding author. Email: buithiminhha@tuaf.edu.vn
} 


\section{1. Đặt vấn đề}

Biến đổi khí hậu $(\mathrm{BĐKH)} \mathrm{đang} \mathrm{là} \mathrm{mối} \mathrm{quan} \mathrm{tâm} \mathrm{lớn} \mathrm{của} \mathrm{cả} \mathrm{nhân} \mathrm{loại,} \mathrm{BĐKH} \mathrm{với} \mathrm{những} \mathrm{tác}$ động tiềm tàng trên tất cả các lĩnh vực kinh tế, xã hội và môi trường đang là thách thức, ảnh hưởng đến sự phát triển bền vững của các quốc gia trên thế giới [1]. Biến đổi khí hậu làm cho người dân gặp phải rất nhiều khó khăn, đặc biệt các hộ có sinh kế phụ thuộc nông nghiệp, thủy sản, du lịch và vận tải [2]. Việt Nam từ lâu được đánh giá là một trong các quốc gia bị ảnh hưởng nặng nề nhất bởi $\mathrm{BĐKH}$ với những biểu hiện về sự gia tăng của mực nước biển, bão, lũ lụt và hạn hán. Biến đổi khí hậu làm tăng tính dễ tổn thương sinh kể nông thôn và làm giảm khả năng của các hộ gia đình đối phó với rủi ro, cú sốc và căng thẳng [3]. Hậu quả của BĐKH đối với Việt Nam là nghiêm trọng và là một nguy cơ hiện hữu cho mục tiêu xoá đói giảm nghèo, cho việc thực hiện các mục tiêu thiên niên kỷ và sự phát triển bền vững của đất nước [4].

Tính dễ bị tổn thương sinh kế do BĐKH có thể được hiểu là kết quả tác động của các yếu tố vật chất và xã hội đến sinh kế hộ hoặc nhóm người bị tổn thương. Các yếu tố về vật chất đề cập đến mức độ các cộng đồng tiếp xúc phải đối mặt với các tác động sinh lý như nước biển dâng, sự gia tăng bề mặt biển hoặc khí quyển nhiệt độ... những tác động này làm gia tăng tính dễ tổn thương sinh kế nông thôn và làm giảm khả năng đối phó với rủi ro, cú sốc và căng thẳng của các hộ gia đình. Các yếu tố về xã hội là một phần của sản phẩm các yếu tố hình thành tính nhạy cảm của cộng đồng để gây tổn hại và chi phối khả năng phản hồi của cộng đồng, góp phần làm tổn thương xã hội của các địa bàn cụ thể [3], [5]. Tổn thương sinh kế do tác động của BĐKH là sự thiệt hại về sinh kế (như việc làm, thu nhập) của con người từ sự thay đổi của các yếu tố khí hậu gây ra. Trong đó, vấn đề được đặc biệt quan tâm là sự xuất hiện của thiên tai và các hiện tượng thời tiết dị thường, với cường độ và tần suất ngày càng cao, có thể gây ra những tổn thất vô cùng to lớn [6].

Đánh giá tính dễ bị tổn thương đối với $\mathrm{BĐKH} \mathrm{là} \mathrm{một} \mathrm{phần} \mathrm{quan} \mathrm{trọng} \mathrm{trong} \mathrm{nỗ} \mathrm{lực} \mathrm{xác}$ định mức độ rủi ro khí hậu và cung cấp thông tin nền tảng cho việc xây dựng các chính sách và hành động nhằm đối phó với các rủi ro, hiểm họa liên quan đến $\mathrm{BĐKH} \mathrm{[7].} \mathrm{Tại} \mathrm{Việt} \mathrm{Nam,}$ các nghiên cứu về tổn thương sinh kế do $\mathrm{BĐKH}$ mới chỉ được thực hiện trong những năm gần đây như nghiên cứu của Nguyễn Văn Bôi và Đoàn Thị Thanh Kiều (2012) [8] thực hiện ở xã đảo Tam Hải, huyện Núi Thành, tỉnh Quảng Nam; nghiên cứu của Nguyễn Quốc Nghi (2016) [1] thực hiện ở vùng ven biển tỉnh Cà Mau; nghiên cứu của Lê Quang Cảnh (2016) [9] tại xã Ngũ Điền, huyện Phong Điền, tỉnh Thừa Thiên Huế; nghiên cứu của Bùi Sỹ Bách (2018) [6] triển khai ở huyện Thạch Hà, tỉnh Nghệ Tĩnh,... Các nghiên cứu chủ yếu mới tập trung đánh giá mức độ ảnh hưởng trực tiếp của $\mathrm{BĐKH,} \mathrm{như} \mathrm{BĐKH} \mathrm{gây} \mathrm{tình} \mathrm{trạng} \mathrm{ngập} \mathrm{lụt,} \mathrm{xâm} \mathrm{nhập}$ mặn gia tăng dẫn đến việc mất đất sản xuất, đe dọa an ninh lương thực đồng thời chỉ ra rằng người dân ven biển là đối tượng dễ bị tổn thương trước tác động của $\mathrm{BĐKH} \mathrm{do} \mathrm{hạn} \mathrm{chế} \mathrm{về}$ năng lực thích ứng trong khi họ thiếu các nguồn lực cần thiết để đương đầu với rủi ro [10]. Như vậy có thể thấy rằng các nghiên cứu chủ yếu triển khai ở vùng nông thôn ven biển, khu vực miền Trung và đồng bằng sông Cửu Long, việc nghiên cứu đánh giá tổn thương sinh kế chưa thật cụ thể và chi tiết, đặc biệt việc triển khai nghiên cứu tại các vùng nông thôn miền núi phía Bắc còn rất hạn chế. Tại Thái Nguyên, nghiên cứu liên quan đến biến đổi khí hậu cũng mới bắt đầu được triển khai trong vài năm gần đây [11]-[13]. Tuy nhiên, trong các nghiên cứu này gần như chưa có nghiên cứu nào đánh giá tổn thương sinh kế do tác động của biển đổi khí hậu triển khai trên địa bàn tỉnh Thái Nguyên.

Định Hoá là huyện miền núi của tỉnh Thái Nguyên, diện tích đất nông lâm nghiệp chiếm trên $74 \%$ diện tích đất tự nhiên. Với hơn 26 nghìn hộ dân sinh sống trên địa bàn, sinh kế chính của người dân chủ yếu dựa rừng và sản xuất nông nghiệp [14]. Với địa hình phức tạp, độ dốc lớn nên huyện Định Hóa luôn có nguy cơ bị ảnh hưởng bởi các loại hình thiên tai như lũ ống, lũ quét, sạt lở đất. Theo thống kê, từ năm 2016 đến nay, trên địa bàn huyện xảy ra 30 đợt thiên tai bao gồm: mưa dông, lũ ống, lũ quét, mưa đá... khiến 8 người chết, 5 người bị thương, 1.698 ngôi nhà bị 
tốc mái, hư hỏng, trên 2.000 ha lúa và hoa màu bị thiệt hại, gần 15 nghìn con gia súc, gia cầm bị nước lũ cuốn trôi, 92 công trình giao thông, thủy lợi, trường học, trạm y tế... bị hư hỏng, thiệt hại ước tính trên 210 tỷ đồng. Chỉ tính riêng năm 2020, trên địa bàn huyện đã xảy ra 4 đợt mưa dông, tố lốc lớn xảy ra đã khiến 11 nhà bị tốc mái, hư hỏng; trên 300 nghìn $\mathrm{m}^{2}$ hoa màu bị thiệt hại; thiệt hại trên 500 nghìn $\mathrm{m}^{2}$ cây lâm nghiệp và gần 200 con gia cầm;... với ước tính thiệt hại trên 2 tỷ đồng. Hiện nay, trên địa bàn huyện vẫn còn trên 2 nghìn hộ dân với trên 8800 nhân khẩu đang sinh sống ở khu vực có nguy cơ xảy ra sạt lở, lũ ống, lũ quét... Trong thời gian tới huyện Định Hóa tiếp tục được xác định sẽ là địa phương chịu ảnh hưởng nặng nề nhất do BĐKH và các loại hình thời tiết cực đoan của tỉnh Thái Nguyên [15].

Trong bối cảnh tài nguyên rừng ngày càng hạn hẹp, diện tích đất nông nghiệp ít cùng với sự gia tăng của $\mathrm{BĐKH}$ và các hiện tượng thời tiết cực đoan, chắc chắn sẽ gây ra những tác động tiêu cực không hề nhỏ tới sinh kế của người dân huyện vùng cao Định Hóa. Với lý do đó, nghiên cứu này được thực hiện nhằm mục đích phân tích tính dễ bị tổn thương sinh kế do tác động của BĐKH đối với người dân tại huyện Định Hóa. Kết quả của nghiên cứu có ý nghĩa quan trọng việc cung cấp thông tin hữu ích cho các cơ quan quản lý trong công tác lập kế hoạch cũng như hoạch định chính sách và triển khai các hành động ứng phó với $\mathrm{BĐKH}$, thích ứng với các hiện tượng thời tiết cực đoan trên địa bàn, bảo đảm bền vững sinh kế cho người dân.

\section{Phương pháp nghiên cứu}

\subsection{Tiếp cận của nghiên cúu}

Hiện nay có nhiều cách tiếp cận để đánh giá tổn thương sinh kế trước BĐKH, tuy nhiên so với các phương pháp định tính thì công cụ định lượng có ưu thế hơn khi đưa ra được các chỉ số tổn thương rõ ràng. Một số phương pháp đã được sử dụng để đo lường mức độ tổn thương sinh kế do BĐKH trong các nghiên cứu như: Chỉ số tổn thương sinh kế - LVI [16], chỉ số tác động đến sinh kế - LEI [17], chỉ số tổn thương khí hậu - CVI [18], chỉ số năng lực thích ứng hiện tại - CVCI. Về cơ bản các phương pháp này đều đánh giá tác động của $\mathrm{BĐKH} \mathrm{đến} \mathrm{sinh} \mathrm{kế} \mathrm{người} \mathrm{dân} \mathrm{tập}$ trung vào hai khía cạnh là tính dễ bị tổn thương và năng lực thích ứng. Trong đó tính dễ bị tổn thương là mức độ cộng đồng không có khả năng đối phó với những tác động bất lợi của BĐKH và năng lực thích ứng là khả năng của cộng đồng thích nghi được với những tác động của $B Đ K H$.

Nghiên cứu này sử dụng phương pháp chỉ số tổn thương sinh kế (LVI) của Hahn và cộng sự, 2009 [16] để đánh giá tổn thương sinh kế của người dân huyện Định Hóa trước BĐKH. Phương pháp này có ưu thể về tập hợp các yếu tố tác động đến sinh kế người dân, bao gồm 7 yếu tố chính: đặc điểm hộ, chiến lược sinh kế, mạng lưới xã hội, sức khỏe, lương thực - thực phẩm, nguồn nước, thiên tai và biến đổi khí hậu. Mỗi yếu tố chính bao gồm nhiều yểu tố phụ, được hình thành dựa trên tổng quan của mỗi yếu tố chính khi tiến hành điều tra, phỏng vấn các hộ dân ở khu vực nghiên cứu và tham vấn chuyên gia trong quá trình thực hiện. Tùy vào điều kiện của khu vực nghiên cứu và nội dung nghiên cứu để đưa ra hệ thống các chỉ số phụ thích hợp.

\subsection{Phương pháp thu thập số liệu}

Số liệu thư cấp: được thu thập từ các tài liệu về khí hậu, các kịch bản và các chính sách, chương trình của Nhà nước liên quan đến $\mathrm{BĐKH}$, các nghiên cứu về sinh kế đã được thực hiện. Bên cạnh đó, nghiên cứu cũng sử dụng các thông tin từ báo cáo phát triển kinh tế - xã hội của các sở, ban, ngành có liên quan trong tỉnh Thái Nguyên.

Số liệu so cấp: được thu thập năm 2021 bằng phương pháp phỏng vấn hộ. Tổng số hộ điều tra của nghiên cứu là 196 hộ, được tính theo công thức của Slovin [19]. Mẫu phỏng vấn được chọn theo phương pháp ngẫu nhiên tại 4 xã: Quy Kỳ, Linh Thông, Lam Vĩ, Tân Thịnh đại diện cho địa bàn vùng cao và 4 xã: Phú Đình, Bình Thành, Điềm Mặc, Bộc Nhiêu đại diện cho địa bàn vùng thấp của huyện Định Hóa. Các xã được lựa chọn đảm bảo tính đại diện về các phương diện điều kiện tự nhiên, kinh tế - xã hội; đặc điểm tình hình nông thôn và nông dân..., đồng thời phù hợp với các mục tiêu của nghiên cứu. 
Nội dung bảng hỏi sử dụng để phỏng vấn hộ bao gồm các câu hỏi đóng và mở xoay quanh các chủ đề như: Đặc điểm của hộ, chiến lược sinh kế, sức khỏe, mạng lưới xã hội, lương thực thực phẩm, tài chính, thiên tai và biến đổi khí hậu $(\mathrm{BĐKH)...}$

\subsection{Phương pháp phân tích số liệu}

\subsubsection{Phân tích chi số dễ bị tổn thương sinh kế (LVI)}

LVI sử dụng cách tiếp cận cân bằng trọng số trung bình, trong đó các yếu tố phụ góp phần như nhau đối với chỉ số tổng thể, mặc dù mỗi yếu tố chính có số lượng các yếu tố phụ khác nhau. Công thức LVI sử dụng cách tiếp cận đơn giản bằng cách áp dụng trọng số bằng nhau cho tất các các yếu tố chính [20].

Cách tính LVI được mô phỏng bởi Hahn và cộng sự (2009) [16], nhưng có một số thay đổi để phù hợp với điều kiện thực tế. Do mỗi yếu tố phụ được đo lường với các đơn vị khác nhau, do vậy trước tiên cần phải chuẩn hóa chúng để có thể so sánh theo biểu thức (1).

$$
\text { Index } S_{d}=\left(S_{d}-S_{\text {min }}\right) /\left(S_{\text {max }}-S_{\text {min }}\right)
$$

Trong đó: $S_{d}$ là giá trị yếu tố phụ; $S_{\min }$ và $S_{\max }$ là giá trị tối thiểu và tối đa (phản ánh tính dễ bị tổn thương tương ứng mức thấp và cao).

Sau khi được chuẩn hóa, các yếu tố phụ được lấy trung bình để tính giá trị của mỗi yếu tố chính bằng biểu thức (2):

$$
M_{d}=\sum_{i=1} \text { index }_{d} i / n
$$

Trong đó: $\mathrm{M}_{\mathrm{d}}$ là 1 hợp phần chính; index $\mathrm{S}_{\mathrm{d}} \mathrm{i}$ đại diện giá trị các chỉ số yếu tố phụ được ghi chỉ số theo i; và n là số lượng yếu tố phụ trong mỗi yếu tố chính.

Khi các giá trị của mỗi yếu tố chính được xác định, chỉ số tổn thương sinh kế được tính theo công thức (3):

$$
L V I_{d}=\left(\sum_{\mathrm{i}=1}^{\mathrm{n}} W_{\mathrm{M} i} M_{d i} / \sum_{\mathrm{i}=1} W_{\mathrm{M} i}\right)
$$

Trong đó, $\mathrm{LVI}_{\mathrm{d}}$ : là chỉ số tổn thương $\sinh$ kế của huyện $\mathrm{d} ; \mathrm{W}_{\mathrm{Mi}}$ : là trọng số của một trong các yếu tố chính.

\subsubsection{Phân tích chỉ số tổng hợp LVI-IPCC}

LVI-IPCC được tính toán áp dụng cùng các chỉ số đã sử dụng trong tính toán LVI (Hahn và cộng sự, 2009) [16]. Ở đây thay vì nhập chung các yếu tố chính lại thành LVI, chúng được chia ra thành 3 nhóm yếu tố dễ bị tổn thương theo khía cạnh phơi bày, nhạy cảm, và khả năng thích ứng với biến đổi khí hậu. Mồi yếu tố trong 3 yếu tố theo IPCC được tính theo công thức sau:

$$
C F d=\left(\sum_{i=1} W_{\mathrm{M} i} M_{d i} / \sum_{i=1} W_{\mathrm{M} i}\right)
$$

Trong đó: CFd là một trong những yếu tố tạo nên LVI-IPCC (phơi bày, nhạy cảm và khả năng thích ứng) cho cộng đồng $\mathrm{d}$; $\mathrm{W}_{\mathrm{Mi}}$ là trọng số cho mỗi yếu tố chính và $\mathrm{M}_{\mathrm{di}}$ là yếu tố chính $\mathrm{i}$ của vùng $\mathrm{d}$. Sau đó VI-IPCC được tính theo công thức sau:

$$
\text { LVI-IPCC }=\left(e_{d}-a_{d}\right) * s_{d}
$$

Trong đó: LVI-IPCCd là chỉ số LVI của tỉnh $\mathrm{d}$ bằng cách sử dụng khung tổn thương của IPCC, (chỉ số LVI-IPPC dao động từ -1 là tổn thương ít nhất đến 1 là tổn thương nhiều nhất); e là mức độ ảnh hưởng; a là năng lực thích ứng và $\mathrm{s}$ là mức độ nhạy cảm của cộng đồng $\mathrm{d}$.

\section{Kết quả và thảo luận}

\section{1. Đánh giá tổn thuơng sinh kế huyện Định Hóa theo chỉ số LVI}

LVI của huyện Định Hóa được cấu thành từ 7 yếu tố chính bao gồm: Đặc điểm hộ; Chiến lược sinh kế; Mạng lưới xã hội; Sức khoẻ; Nguồn nước; Lương thực - thực phẩm; Thiên tai và biến đổi khí hậu. Dựa vào 7 yếu tố chính này, nghiên cứu đưa ra 31 yếu tố phụ, giá trị của các yếu tố phụ của LVI được thể hiện chi tiết ở bảng 1 . 
Bảng 1. Giá trị các yếu tố phụ của LVI huyện Định Hóa

\begin{tabular}{|c|c|c|c|c|}
\hline \multirow{2}{*}{$\begin{array}{l}\text { Các } \\
\text { yếu tố } \\
\text { chính }\end{array}$} & \multirow[b]{2}{*}{ Các yếu tố phụ } & \multicolumn{3}{|c|}{ Giá trị các yếu tố phụ } \\
\hline & & $\begin{array}{c}\text { Các xã } \\
\text { vùng cao }\end{array}$ & $\begin{array}{l}\text { Các xã } \\
\text { vùng thấp }\end{array}$ & $\begin{array}{c}\text { Huyện } \\
\text { Định Hóa }\end{array}$ \\
\hline \multirow{4}{*}{$\begin{array}{c}\text { Đặc } \\
\text { điểm } \\
\text { hộ }\end{array}$} & Tỷ lệ hộ có nhân khẩu phụ thuộc & 0,238 & 0,142 & 0,190 \\
\hline & Tỷ lệ hộ có chủ hộ là nữ & 0,138 & 0,242 & 0,190 \\
\hline & Tỷ lệ hộ có thành viên có thu nhập ổn định (lương, trợ cấp..) & 0,045 & 0,040 & 0,043 \\
\hline & Tỷ lệ hộ có chủ hộ chưa học hết phổ thông cơ sở & 0,700 & 0,583 & 0,642 \\
\hline \multirow{4}{*}{$\begin{array}{l}\text { Chiến } \\
\text { lược } \\
\text { sinh kế }\end{array}$} & Tỷ lệ hộ có sinh kế chính dựa vào nông lâm nghiệp & 0,962 & 0,917 & 0,939 \\
\hline & Tỷ lệ hộ không có khả năng tích lũy & 0,854 & 0,625 & 0,739 \\
\hline & Chỉ số đa dạng sinh kế nông nghiệp trung bình & 0,006 & 0,006 & 0,006 \\
\hline & Tỷ lệ hộ không có thành viên đi làm bên ngoài xã & 0,477 & 0,800 & 0,638 \\
\hline \multirow{5}{*}{$\begin{array}{l}\text { Mạng } \\
\text { lưới } \\
\text { xã hội }\end{array}$} & Chỉ số đa dạng phương tiện thông tin & 0,240 & 0,175 & 0,208 \\
\hline & $\begin{array}{l}\text { Tỷ lệ hộ không có người tham gia vào tổ chức chính trị xã hội của } \\
\text { địa phương }\end{array}$ & 0,951 & 0,892 & 0,922 \\
\hline & Tỷ lệ hộ cần giúp đỡ từ chính quyền khi thiên tai & 0,643 & 0,572 & 0,608 \\
\hline & Tỷ lệ hộ tham gia liên kết trong sản xuất & 0,178 & 0,116 & 0,147 \\
\hline & Tỷ lệ hộ không tiếp cận được thông tin qua các phương tiện truyền thông & 0,253 & 0,045 & 0,149 \\
\hline \multirow{4}{*}{$\begin{array}{l}\text { Sức } \\
\text { khỏe }\end{array}$} & Khoảng cách từ nhà tới cơ sở y tế gần nhất & 0,063 & 0,034 & 0,048 \\
\hline & Tỷ lệ hộ có người cần chăm sóc & 0,362 & 0,333 & 0,347 \\
\hline & Tỷ lệ hộ có người mắc bệnh mãn tính & 0,300 & 0,342 & 0,321 \\
\hline & Tỷ lệ hộ có thành viên nghỉ học/làm do ốm từ 7 ngày trở lên trong năm & 0,238 & 0,317 & 0,278 \\
\hline \multirow{4}{*}{$\begin{array}{l}\text { Lương } \\
\text { thực - } \\
\text { thực } \\
\text { phẩm }\end{array}$} & Tỷ lệ hộ chỉ dùng thực phẩm do gia đình sản xuất & 0,180 & 0,275 & 0,228 \\
\hline & Tỷ lệ hộ chỉ dùng lương thực do gia đình sản xuất & 0,954 & 0,833 & 0,894 \\
\hline & Tỷ lệ hộ gặp khó khăn về lương thực - thực phẩm & 0,437 & 0,075 & 0,256 \\
\hline & Tỷ lệ hộ không dự trữ lương thực quanh năm & 0,211 & 0,092 & 0,151 \\
\hline \multirow{3}{*}{$\begin{array}{l}\text { Nguồn } \\
\text { nước }\end{array}$} & Tỷ lệ hộ không được sử dụng nguồn nước ổn định & 0,156 & 0,045 & 0,101 \\
\hline & Tỷ lệ hộ chỉ sử dụng nguồn nước tự nhiên cho sinh hoạt & 0,572 & 0,242 & 0,407 \\
\hline & Tỷ lệ hộ gặp khó khăn về nguồn nước cho sản xuất & 0,229 & 0,137 & 0,183 \\
\hline \multirow{7}{*}{$\begin{array}{l}\text { Thiên } \\
\text { tai và } \\
\text { BĐKH }\end{array}$} & Số lần bão, lũ, hạn... trong 5 năm qua & 0,500 & 0,471 & 0,486 \\
\hline & Tỷ lệ hộ không nhận được cảnh báo thiên tai & 0,215 & 0,116 & 0,166 \\
\hline & Tỷ lệ hộ bị thiệt hại về nhà cửa do thiên tai gây ra trong 5 năm gần nhất & 0,327 & 0,232 & 0,279 \\
\hline & Tỷ lệ hộ có người chết hoặc bị thương do thiên tai trong 5 năm gần nhất & 0,054 & 0,000 & 0,027 \\
\hline & $\begin{array}{l}\text { Tỷ lệ hộ nhận thấy sự thay đổi bất thường của thiên tai, khí hậu tại } \\
\text { địa phương }\end{array}$ & 0,902 & 0,932 & 0,917 \\
\hline & Tỷ lệ hộ có nhà không kiên cố dễ bị ảnh hưởng bởi gió lốc, mưa đá... & 0,317 & 0,178 & 0,248 \\
\hline & Tỷ lệ hộ có nhà nằm ở nơi dễ bị sạt lở đất, lũ lụt,... & 0,432 & 0,182 & 0,307 \\
\hline
\end{tabular}
(Nguồn: Kết quả nghiên cúu, 2021)

Từ kết quả giá trị của các yếu tố phụ tại bảng 1, giá trị LVI huyện Định Hóa được tổng hợp và trình bày tại bảng 2 :

Bảng 2. Giá trị các yếu tố chính của LVI huyện Định Hóa

\begin{tabular}{|c|c|c|c|c|c|}
\hline \multirow{2}{*}{$\begin{array}{l}\text { Nhân tố } \\
\text { đóng góp }\end{array}$} & \multirow{2}{*}{ Các yếu tố chính } & \multirow{2}{*}{$\begin{array}{l}\text { Số yếu } \\
\text { tố phụ }\end{array}$} & \multicolumn{3}{|c|}{ Giá trị của các yếu tố chính } \\
\hline & & & Các xã vùng cao & Các xã vùng thấp & Huyện Định Hóa \\
\hline \multirow{4}{*}{ Thích ứng (a) } & Đặc điểm hộ gia đình & 4 & 0,281 & 0,252 & 0,266 \\
\hline & Chiến lược sinh kế & 4 & 0,574 & 0,587 & 0,581 \\
\hline & Mạng lưới xã hội & 5 & 0,453 & 0,360 & 0,407 \\
\hline & Sức khỏe & 4 & 0,241 & 0,241 & 0,241 \\
\hline \multirow[t]{2}{*}{ Nhạy cảm (s) } & Nguồn nước & 3 & 0,319 & 0,141 & 0,230 \\
\hline & Lương thực - thực phẩm & 4 & 0,446 & 0,319 & 0,382 \\
\hline \multirow[t]{2}{*}{ Tổn thương (e) } & Thiên tai và BĐKH & 7 & 0,392 & 0,302 & 0,347 \\
\hline & LVI(*) & & $\mathbf{0 , 4 3 3}$ & $\mathbf{0 , 3 3 8}$ & 0,386 \\
\hline
\end{tabular}

(Nguồn: Kết quả nghiên cúu, 2021)

(*): Giá trị LVI dao động tù mưc 0 (mức tổn thương thấp nhất) đến 0,5 (mức tổn thương cao nhất) 
Kết quả nghiên cứu tại bảng 2 cho thấy:

Yếu tố chiến lược sinh kế: Là yếu tố có giá trị LVI cao nhất $(0,581)$ trong 7 yếu tố chính, đồng nghĩa với việc yếu tố này bị tổn thương nhiều nhất trước $\mathrm{BĐKH.} \mathrm{Mức} \mathrm{độ} \mathrm{tổn} \mathrm{thương} \mathrm{của} \mathrm{chiến}$ lược sinh kế dựa vào mức độ tổn thương của 4 yếu tố phụ (bảng 1), trong đó có 3 yếu tố phụ có giá trị rất cao là tỷ lệ hộ có sinh kế chính dựa vào sản xuất nông lâm nghiệp $(0,939)$, tỷ lệ không có khả năng tích lũy $(0,739)$ và tỷ lệ hộ không có người đi làm bên ngoài làng xã $(0,638)$. Nguyên nhân là do các hộ dân trong huyện Định Hóa có sinh kế chủ yếu dựa vào sản xuất nông lâm nghiệp, một loại hình sản xuất chịu ảnh hưởng rất lớn vào các điều kiện khách quan từ thị trường và các điều kiện thời tiết, khí hậu, do vậy thu nhập thấp, không ổn định và ít có tích lũy.

Yếu tố mang lưới xã họi: Là yếu tố có giá trị LVI cao thứ $2(0,407)$. Yếu tố này là chỉ số tổng hợp của 5 yếu tố phụ, trong đó có 2 yếu tố phụ có giá trị rất cao là tỷ lệ hộ không có người tham gia vào tổ chức chính trị xã hội của địa phương $(0,922)$ và tỷ lệ hộ có nhu cầu giúp đỡ từ chính quyền khi thiên tai $(0,608)$. Điều này thể hiện tính gắn kết cộng đồng không cao, mặc dù các địa bàn nghiên cứu đều có tổ chức chính trị xã hội nhưng sự tham gia của người dân vào các tổ chức này lại rất hạn chế, hoạt động các tổ chức xã hội chưa thực sự hiệu quả. Bên cạnh đó các hộ cũng chưa có sự liên kết trong các hoạt động sinh kế nên chưa chủ động được trong sản xuất và gia tăng giá trị nông sản.

Yểu tố luoong thực - thực phẩm: Là yếu tố có giá trị LVI cao thứ $3(0,382)$. Yếu tố này có ảnh hưởng rất lớn từ giá trị yếu tố phụ là tỷ lệ hộ chỉ sử dụng lương thực do gia đình tự sản xuất $(0,894)$. Giá trị của chỉ số này có được do thực tế điều tra cho thấy có đến gần $90 \%$ số hộ trên địa bàn tự túc lương thực, hoặc chỉ sử dụng các loại lương thực do gia đình sản xuất như gạo, ngô, khoai, sắn... và hầu như không phải mua bên ngoài. Tuy nhiên do thói quen, tập quán sinh hoạt hầu như các hộ lại không tích trữ lương thực - thực phẩm, do vậy trong điều kiện sản xuất không thuận lợi thì yếu tố này sẽ bị tổn thương rất lớn.

Yếu tố thiên tai và biến đổi khi hậu: Là yếu tố có giá trị LVI cao thứ $4(0,347)$, chỉ số này ở mức trên trung bình, tuy nhiên có thể thấy yếu tố phụ tỷ lệ hộ nhận thấy sự thay đổi bất thường của thiên tai, khí hậu tại địa phương có giá trị rất lớn $(0,917)$ là do trên $90 \%$ số hộ điều tra tại các điểm nghiên cứu đều nhận thấy những bất thường của thời tiết khí hậu đang diễn ra tại địa phương như nhiệt độ ngày càng cao, thời gian nắng nóng kéo dài và gay gắt hơn, mùa mưa ngắn hơn nhưng lượng mưa lại lớn hơn, thời gian khô hạn cũng kéo dài hơn trước, các hiện tượng lũ lụt, ngập úng, sạt lở đất cục bộ diễn ra thường xuyên hơn. Như vậy có thể thấy trong bối cảnh $\mathrm{B} Đ K H$ chắc chắn rằng yếu tố thiên tai và biến đồi khí hậu sẽ ngày càng gia tăng mức độ tổn thương.

Các yếu tố: đặc điểm hộ, sức khỏe và nguồn nước có giá trị lần lượt: 0,$266 ; 0,241,0,230$. Đây là 3 yếu tố có giá trị thấp nhất, đồng nghĩa với mức tổn thương nhỏ nhất. Điều này cho thấy điều kiện của người dân đã được cải thiện, không còn hộ không biết chữ, điều kiện chăm sóc sức khỏe cũng được người dân được quan tâm và nguồn nước cho sinh hoạt không phải là vấn đề khó khăn lớn đối với người dân tại địa phương nghiên cứu.

Dựa vào kết quả bảng 2 cũng cho giá trị tổn thương sinh kế LVI của huyện Định Hóa là 0,386 đồng nghĩa với mức độ tổn thương khá cao, các xã vùng cao mức độ tổn thương cao hơn các xã vùng thấp với giá trị lần lượt là 0,433 và 0,338 . Mức độ tổn thương của các yếu tố chính giảm dần theo thứ tự lần lượt là chiến lược sinh kế, mạng lưới xã hội, lương thực- thực phẩm, thiên tai và biến đổi khí hậu, đặc điểm hộ, sức khỏe, nguồn nước.

Về mức độ tổn thương của 7 yếu tố chính trong LVI huyện Định Hóa của từng địa điểm nghiên cứu, kết quả được thể hiện qua hình 1 .

Hình 1 cho thấy mức độ tổn thương của 7 yếu tố chính tại các địa điểm nghiên cứu như sau:

Có hai yếu tố là chiến lược sinh kế và sức khỏe có giá trị tương đương nhau giữa các xã vùng cao và các xã vùng thấp trong huyện, điều này có nghĩa là với hai yếu tố này mức độ tổn thương của tất cả các địa bàn trong huyện là như nhau.

Có ba yếu tố đó là đặc điểm hộ, lương thực - thực phẩm, thiên tai và biến đổi khí hậu đều có giá trị cao hơn các xã vùng cao, tuy nhiên mức độ chênh lệch không lớn, vì vậy mức độ tổn 
thương của ba yếu tố này giữa các xã vùng cao và các xã vùng thấp không có sự khác biệt nhiều.

Nguồn nước là yếu tố ít bị tổn thương nhất trong 7 yếu tố chính, đối với các xã vùng cao mức độ tổn thương nguồn nước cao hơn các xã vùng thấp với giá trị lần lượt là $(0,319$ và 0,141$)$, quá trình điều tra cho thấy nguyên nhân là ở các xã vùng cao do đặc điểm địa hình và tập quán sinh hoạt nên vẫn có $57,2 \%$ số hộ đang sử dụng nguồn nước tự nhiên, trong khi đó các xã vùng thấp đa số các hộ có nguồn nước sinh hoạt ổn định, đảm bảo chất lượng, nhiều hộ đã sử dụng nước máy vì vậy làm gia tăng mức độ chênh lệch giá trị của yếu tố này giữa các xã vùng cao và các xã vùng thấp.

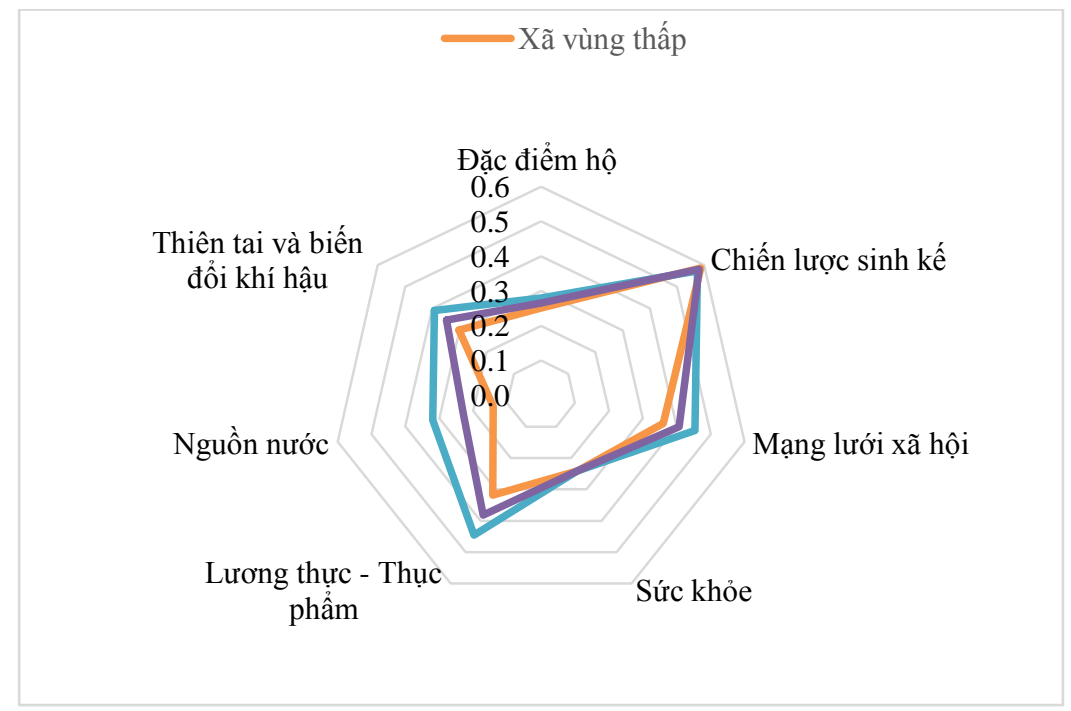

Hình 1. Biểu diễn các yếu tố của chính LVI ở huyện Định Hóa (Nguồn: Phân tích kết quả nghiên cứu, 2021)

Ghi chú: Các giá trị này dao động tù 0 (mức tổn thương thấp nhất) ở trung tâm đến 0,6 (mức tổn thương cao nhất) ở vùng ngoài và khoảng dao động là 0,1 .

\section{2. Đánh giá tổn thuơng sinh kế huyện Định Hóa theo chỉ số LVI -IPCC}

Để đánh giá ảnh hưởng của $\mathrm{BĐKH} \mathrm{tới} \mathrm{sinh} \mathrm{kế} \mathrm{của} \mathrm{người} \mathrm{dân} \mathrm{huyện} \mathrm{Định} \mathrm{Hóa,} \mathrm{chỉ} \mathrm{số} \mathrm{tổn}$ thương cũng được kết hợp với định nghĩa khả năng tổn thương theo IPCC. Kết quả tính chỉ số LVI-IPCC của huyện Định Hóa được thể hiện ở bảng 3.

Bảng 3. Chỉ số LVI-IPCC huyện Định Hóa

\begin{tabular}{lcccc}
\hline \multicolumn{1}{c}{ Nhân tố LVI-IPCC } & \multirow{2}{*}{$\begin{array}{c}\text { Số lượng } \\
\text { yếu tố phụ }\end{array}$} & \multicolumn{3}{c}{ Giá trị chỉ số LVI-IPCC } \\
\cline { 3 - 5 } & 7 & 0,392 & Các xã vùng cao Các xã vùng thấp & Huyện Định Hóa \\
\hline Sự phơi bày/sự phơi nhiễm (e) & 13 & 0,437 & 0,302 & 0,347 \\
Khả năng thích ứng (a) & 11 & 0,337 & 0,397 & 0,417 \\
Sự nhạy cảm/tính dễ tổn thương (s) & $\mathbf{3 1}$ & $\mathbf{- 0 , 0 1 5}$ & 0,242 & 0,289 \\
LVI-IPCC (*) & & $\mathbf{- 0 , 0 2 3}$ & $\mathbf{- 0 , 0 2 0}$ \\
\hline
\end{tabular}

(Nguồn: Kết quả phân tích số liệu điều tra, 2021)

(*)LVI - IPCC nằm trong khoảng -1 (ít bị tổn thwơng nhất) đến +1 (tổn thuơng nhiều nhất)

Chỉ số LVI-IPCC của người dân huyện Định Hóa là $-0,020$ cho thấy khả năng tổn thương không quá cao, tuy nhiên chỉ số này có sự chênh lệch, ở các xã vùng cao giá trị chỉ số LVI-IPCC $(-0,015)$ lớn rất nhiều giá trị LVI-IPCC ở các xã vùng thấp $(-0,023)$. Cụ thể 3 nhân tố trong LVIIPCC được thể hiện qua tam giác tổn thương hình 2.

Kết quả hình 2 cho thấy huyện Định Hóa đang chịu tác động khá nặng nề của BĐKH, sự phơi bày và sự nhaỵ cảm tương đối cao với các giá trị lần lượt là 0,310 và 0,292 .

Khả năng thích ứng có giá trị 0,417 cho thấy người dân tại địa phương có năng lực thích ứng 
tương đối tốt với $\mathrm{BĐKH}$, kết quả này có được chính bởi sự nỗ lực của chính quyền và người dân địa phương, đây chính là tiền đề và cơ sở để huyện Định Hóa tiếp tục duy trì và phát huy các giải pháp ứng phó với $\mathrm{BĐKH} \mathrm{trong} \mathrm{thời} \mathrm{gian} \mathrm{tới.}$

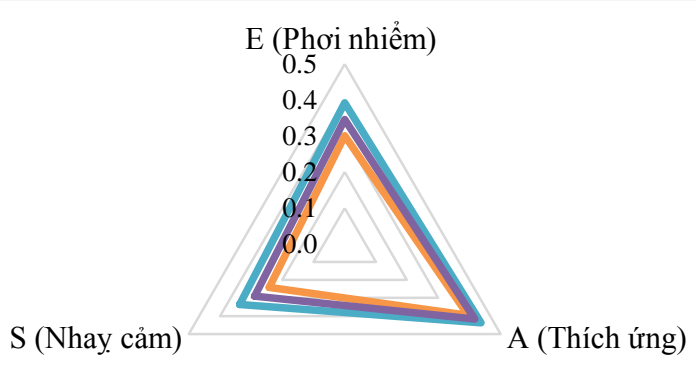

\section{Kết luận}

Hình 2. Các nhân tố LVI- IPCC huyện Định Hóa

(Nguồn: Kết quả phân tích số liệu điều tra, 2021)

Chỉ số LVI huyện Định Hoá có giá trị 0,386 cho thấy mức độ tổn thương khá cao. LVI được hình thành từ 7 yếu tố chính, khả năng tổn thương của các yếu tố chính giảm dần theo thứ tự: chiến lược sinh kế, mạng lưới xã hội, lương thực - thực phẩm, thiên tai và $\mathrm{BĐKH}$, đặc điểm hộ, sức khỏe và nguồn nước với các giá trị lần lượt: 0,$581 ; 0,407 ; 0,382 ; 0,347 ; 0,266 ; 0,241$ và 0,230 .

Chỉ số LIV- IPCC là sự góp mặt của 3 yếu tố: sự phô bày, khả năng thích ứng, sự nhạy cảm/tính dễ bị tổn thương. Kết quả nghiên cứu chỉ ra rằng sự phô bày và sự nhạy cảm trước tác động của biến đổi khí hậu tại địa phương là tương đối cao, đạt giá trị lần lượt là 0,310 và 0,292 , nhưng ngược lại khả năng thích ứng của người dân tương đối tốt với giá trị là 0,417 . Chỉ số LVI IPCC của người dân huyện Định Hóa có giá trị $-0,020$ cho thấy khả năng tổn thương trước BĐKH không quá cao. Nhìn chung người dân đã nhận thức được những ảnh hưởng bất lợi của thiên tai và $\mathrm{BĐKH}$ tới đời sống sinh kế nên luôn chủ động phòng tránh. Tuy nhiên bản chất của chỉ số LVI-IPCC mang tính thời điểm, trong khi đó thiên tai và $\mathrm{BĐKH} \mathrm{mang} \mathrm{tính} \mathrm{dài} \mathrm{hạn} \mathrm{và}$ ngày một gia tăng vì vậy người dân cần chủ động nắm bắt thông tin về $\mathrm{BĐKH}$ và tăng cường các biện pháp phòng tránh để giảm thiểu thiệt hại do tác động của BĐKH gây ra đảm bảo sinh kế ổn định và bền vững.

Hạn chế của nghiên cứu này là các yếu tố phụ của LVI được lựa chọn dựa vào kinh nghiệm của cộng đồng, ý kiến chuyên gia và những người $a m$ hiểu về $\mathrm{BĐKH}$, thiên tai và sinh kế tại địa phương. Do vậy kết quả nghiên cứu có hạn chế về mặt không gian khi muốn so sánh với các nghiên cứu tại các địa bàn khác nhau. Các kết quả nghiên cứu cũng chỉ có thể so sánh được trong cùng một nghiên cứu khi cùng bộ công cụ, cùng chọn yếu tố phụ giống nhau, không thể so sánh được giữa các nghiên cứu khác. Vì vậy, cần thiết phải tiếp tục nghiên cứu chuẩn hóa các yếu tố phụ để có thể thực hiện so sánh các kết quả nghiên cứu khi thực hiện ở những địa bàn khác nhau. Ngoài ra, việc phỏng vấn ngẫu nhiên các hộ dân tại khu vực nghiên cứu cũng có hạn chế về độ tin cậy của số liệu sơ cấp, vì vậy để khắc phục hạn chế này nghiên cứu cần phải tăng dung lượng mẫu điều tra và áp dụng phương pháp thống kê để loại bỏ sai số.

\section{TÀI LIẸU THAM KHẢO/ REFERENCES}

[1] Q. N. Nguyen, “Assessing Vulnerability to climate change impacts on liverlihood coastal communities in Ca Mau province," Journal of forestry science and technology, no. 4, pp. 133-140, 2016.

[2] C. Reid, Rapid Assessment of the Extent and impact of sea level rise in Viet Nam. ICEM-Interenational centre for Enviromental management. Indoorpilly, Queensland, Australia, 2008.

[3] M. Prowse and L. Scott, "Assets and adaptation: an emerging debate," Lund University, IDS Bulletin, vol. 39, no. 4, pp. 42-52, 2008. 
[4] T. H. G. Nguyen, H. D. Ha, H. T. Thanh, and Q. T. Nguyen, "Research on Livelihood Vulnerability of fishermen in the context of climate change - A case study in Huong Phong commune, Huong Tra town, Thua Thien Hue province, Viet Nam," Vinh University Scientific Journal, vol. 47, no. 3A, pp. 28-45, 2018.

[5] S. L. Cutter, J. T. Mitchell, and M. S. Scott, "Revealing the vulnerability of people and places: a case study of Georgetown County, South Carolina," Annals of the Association of American Geographers, vol. 90, no. 4, pp. 713-737, 2000.

[6] S. B. Bui, T. T. H. Hoang, and T. X. T. Nguyen, "Stuady on livelihood vulnerability assessment to climate change in coastal communes ò Thach Ha district, Ha Tinh province," Journal of climate change science, no. 5, pp. 20-26, March 2018.

[7] T. E. Downing and R. J. A. Patwardhan, Assessing vulnerability for climate adaptation. Cambridge University Press, London, UK, 2005.

[8] Q. B. Nguyen and T. T. K. Doan, "Applying Livelihood Vulnerability Index in studying livelihood case of Tam Hai commune, Nui Thanh district, Quang Nam province," Science Journal of Can Tho University, no. 22b, pp. 251-260, 2012.

[9] Q. C. Le et al, "Livelihood vulnerability index in assesing vulnerrability due to climate change in Ngu Dien region, Phong Dien district, Thua Thien Hue province," Hue University Science Review, vol. 120, no. 6, pp. 41-51, 2016.

[10] T. D. Tran et al, Climate change and coastal livelihoods. Publishing House Transport, Hanoi, 2012.

[11] T. M. H. Bui and T. H. Nguyen, "Awareness of household on climate change and its effectiveness on tea cultivation: A case study in Tan Cuong tea area, Thai Nguyen city," TNU Journal of Science and Technology, vol. 172, no. 12/2, pp. 63-68, 2017.

[12] D. T. Nguyen, H. T. Ngo, and T. X. Nguyen, "Solutions for adptation to clamate change of housing in rual mountainous areas in Thai Nguyen province," TNU Journal of Science and Technology, vol. 189, no. 13, pp. 211-216, 2018.

[13] M. T. Ha, V. L. Ha, T. T. H. Hoang, T. H. Pham, T. T. H. Khuat, and H. Q. Pham "Identifying potential climate-smart production models in Binh Long commune, Vo Nhai district, Thai Nguyen province," TNU Journal of Science and Technology, vol. 225, no. 10, pp. 113-118, 2020.

[14] H. K. Phuong, A. T. Do, V. T. Nguyen, H. L. Dinh, and D. D. Nguyen, "Forest management situation Dinh Hoa District of Thai Nguyen Province," TNU Journal of Science and Technology, vol. 88, no. 12, pp. 9-15, 2011.

[15] Dinh Hoa District Peoples Committee, Report No.389/BC - UBND: on implementation of socioeconomic development tasks in 2020; orientation and key tasks in 2021, December 15, 2020.

[16] M. B. Hahn, A. M. Riederer, and S. O. Foster, "The Livelihood Vulnerability Index: A pragmatic approach to assessing risks from climate variability and change-a case study in Mozambique," Global Environmental Change, vol. 19, pp. 74-88, 2009.

[17] A. A. Urothody and H. O. Larsen, "Measuring climete change vulnerability: a comparison of two indexes," Banko Janakari, vol. 20, no. 1, pp. 16-9, 2010.

[18] R. Pendey and S. Jha, "Climate vulnerability index-measure of climate change vulnerabilit to communities: a case of rural Lower Himalaya, India," Mitigation and Adaptation Strategies for Global Change, vol. 17, no. 5, pp. 487-506, 2012.

[19] T. T. L. Vo, Methodolgy textbook scientific research methods and outline writing reseach. Can Tho University Publishing House, 2010.

[20] C. Sullivan, Global change impacts: Assessing human vulnerability at the sub-national scale. In: International River Symposium. Brisbane, Australia, 2006. 